\title{
A QUALIDADE NA ATENÇÃO À SAÚDE DA MULHER IDOSA: UM RELATO DE EXPERIÊNCIA
}

The quality concerning to health care for elderly women: An experience report.

La calidad en la atención a la salud de la mujer anciana: un relato de experiencias.

Maria Aparecida Vasconcelos Moura ${ }^{1}$

Ana Maria Domingos ${ }^{2}$

Maria Elizabete de Castro Rassy ${ }^{3}$

\section{RESUMO}

Relato de experiências sobre a assistência integral a mulheres idosas em um Programa de Extensão desenvolvido no Hospital Escola da Universidade Federal do Rio de Janeiro. Apresenta uma proposta pedagógica e assistencial de elevado significado social e de formação acadêmica resultado do empenho de uma equipe de profissionais. Descreve o perfil do idoso que procura 0 serviço especializado e analisa a situação da atenção, com enfoque na melhoria da qualidade da assistência prestada. Utilizaramse os conceitos da Qualidade em Saúde e o Pacto pela Vida. Responde o porquê deste espaço, construído para o desenvolvimento de ações sob a visão de um modelo humanizado, em que as enfermeiras se apoiam nas práticas de educação em saúde. Concluiuse que a proposta pedagógica é um instrumento da atenção e possibilita analisar as expectativas e necessidades da clientela em uma perspectiva da melhoria da qualidade de vida e de saúde, buscando o nível de satisfação da clientela.

Palavras-chave: Enfermagem. Saúde do Idoso. Qualidade

\begin{abstract}
Report of experiences on the integral care to elderly women in an Extension Program developed at the School Hospital of the Federal University of the Rio de Janeiro. It presents a pedagogic and assistance proposal with a high social significance and an academic formation, which was a result from the commitment of a high skilled team of professionals. It describes the profile of the elderly that search for the specialized service and analyze the situation of the care it self, focused in the improvement of the quality in the assistance provided. They have used the concepts of the Health Quality and the Pact for Life. It answers why this space exists, built for the development of actions under the vision of a humanized model, where the nurses support themselves in the practices of education in health. It concludes that the pedagogical proposal is a care tool, making it possible to analyze the expectations and needs of the customer from a perspective of the improvement of life quality, searching for the level of customer's satisfaction.
\end{abstract}

Keywords: Nursing. Health of the elderly. Quality.

\section{Resumen}

Relato de experiencias sobre la asistencia integral a mujeres ancianas en un Programa de Extensión desarrollado en el Hospital Escuela de la Universidade Federal do Rio de Janeiro. Presenta una propuesta pedagógica y asistencial de elevado significado social y de formación académica, resultado del empeño de un equipo de profesionales. Describe el perfil del anciano que procura el servicio especializado y analiza la situación de la atención, con enfoque en la mejoría de la calidad de la asistencia prestada. Se utilizaron los conceptos de la Calidad en Salud y el Pacto de Vida. Responde el por que de este espacio, construido para el desarrollo de acciones bajo la visión de un modelo humanizado, donde las enfermeras se apoyan en las prácticas de educación en salud. Se concluyó que la propuesta pedagógica es un instrumento de la atención, posibilita analizar las expectativas y necesidades de la clientela en una perspectiva de la mejoría de la calidad de vida y de salud, buscando el nivel de satisfacción de la clientela.

Palabras Claves: Enfermería. Salud del anciano. Calidad.

'Doutora em Enfermagem. Professora Associada III do Programa do Departamento de Enfermagem Materno-Infantil. Pesquisadora do NUPESM. Coordenadora Adjunta de Pesquisa e Desenvolvimento da EEAN/UFRJ. Rio de Janeiro-RJ. Brasil. E-mail: maparecidavas@yahoo.com.br, ${ }^{2}$ Doutora em Enfermagem. Professora Adjunta I do Departamento de Enfermagem em Saúde Pública. Especialista em Gerontologia. Coordenadora Acadêmica do PAIPI. Rio de Janeiro- RJ. Brasil. E-mail: anamariadomingos@terra.com.br, ${ }^{3}$ Doutoranda da EEAN/UFRJ. Professora Assistente III do Departamento de Enfermagem Hospitalar da Universidade do Estado do Pará. Membro do NUPESM. Belém-PA. Brasil. E-mail: beterassy6@hotmail.com 


\section{INTRODUÇÃO}

0 contexto brasileiro tem sido marcado por profundas mudanças no cenário demográfico, epidemiológico, político, econômico e social, e a preocupação com a saúde da pessoa idosa ocupou um importante espaço nesse cenário. Por um lado, a criação do Sistema Único de Saúde (SUS), com a reforma sanitária iniciada há algumas décadas no Brasil, nos mostra alguns avanços na efetivação do direito humano à saúde e, de outro, pesquisas como de Figueiredo et al.(2006); Martins e Massorollo (2008), que apresentam resultados positivos sobre a problemática existente. Mesmo diante dessa situação, embora nem sempre identificado pelos idosos, ainda encontramos situações que nos afligem como a violência contra o idoso, praticada na esfera doméstica, pública e institucional. Este quadro nos mostra que é necessário e urgente melhorar a cobertura e a qualidade da atenção básica de saúde, especialmente através da família, entre outros aspectos.

Os desafios para enfrentamento destes e outros problemas não dependem de soluções rápidas ou de curto prazo, mas requerem um planejamento de ações estruturais de médio e longo prazo que possam dar conta de enfrentar uma herança histórica brasileira que, por muitos anos, impediu 0 reconhecimento dos direitos da grande maioria da população. Essas circunstâncias e as contradições delas decorrentes trouxeram reflexos para a sociedade, especialmente no que se refere à política de saúde do idoso e dos demais setores da área social, destacando-se, entre outras consequências de especial interesse para este estudo, a melhoria da qualidade de vida para aqueles que já envelheceram ou que estão em processo de envelhecimento. Percebemos que ainda estamos longe de se obter a manutenção da autonomia enquanto cidadãos, tarefa complexa dessa conquista social para os idosos.

Nessa perspectiva analítica, quando se reflete sobre a situação do idoso, fica muito claro que as suas lideranças, junto a movimentos populares, ofereceram inegável contribuição para ampliar o debate e lutar pela concretização de direitos sociais que, historicamente, permaneciam apenas no plano formal/ legal. Ao mesmo tempo, ocuparam espaço importante na busca de aç̃̃es concretas que garantissem a reversão de modelos político-administrativos autoritários, centralizadores e excludentes, passando a enfatizar, entre outros aspectos, a dimensão coletiva e de participação democrática.

Nesse contexto que devem ser entendidas as medidas de caráter político, de proteção integral e de direitos fundamentais como as veiculadas na Política Nacional do Idoso ${ }^{1}$ e no Estatuto do Idoso, ${ }^{2}$ em cuja formulação encontrase efetiva mudança conceitual. Além disso, acreditamos que tal contextualização seja relevante, pois acrescenta alguns elementos para que se compreendam as ações planejadas e que propõem a assistir o idoso na luta por seu direito à saúde e a melhorar a qualidade de vida e saúde em nossa sociedade.
Tendo presente a relevância dos programas de atenção a saúde do idoso no redirecionamento do discurso oficial relativo à sua atenção, é importante acrescentar que essas iniciativas foram simultâneas à reorientação de tendências, debates e propostas de assistência à saúde veiculadas no plano nacional e internacional numa perspectiva de qualidade de vida dessa população. Esse aspecto é abordado no contexto de surgimento do pacto pela saúde ao descrever que a finalidade da atenção à saúde do idoso é:

Contribuir na qualificação de um conjunto de questões que ainda são entraves na implementação e funcionamento do SUS e que o pacto é uma possibilidade de avançarmos no processo da reforma sanitária iniciadas há poucas décadas no Brasil; acrescenta, ainda, que cabe aos sujeitos sociais, que tem compromisso com o direito humano à saúde, o indiscutível papel de transformar essa possibilidade em realidade ${ }^{3}$.

Igualmente, expressa o propósito de favorecer a assistência integral ao idoso e as suas reais necessidades, sejam físicas, morais, sociais, culturais e/ou garantia de direitos, principalmente em suas demandas específicas, como saúde, lazer, educação, livre participação social, entre outras. Entretanto, destacamos a desigualdade de acesso aos serviços de saúde, a incompatibilidade entre necessidades de saúde da população específica e a oferta aos serviços; a baixa produtividade dos recursos existentes, especialmente considerando-se a relação custo-benefício, o que é indiscutível pela qualidade insatisfatória da assistência e pelas próprias estatísticas referentes a queixas de saúde no envelhecimento e aos tipos de doenças. Segundo pesquisa com idosos no Brasil, os Indicadores do SUS ${ }^{4}$ sobre saúde no envelhecimento mostram que $81 \%$ dos idosos se queixam de alguma doença, e apenas $19 \%$ não apresentam queixa. Relata-se que, na faixa etária entre 60 a 69 anos, as principais queixas são pressão alta/ hipertensão arterial(49\%), problema de vista(22\%) e dores nas costas (26\%), e este quadro de valores aumenta na faixa etária entre 70 e 79 anos, com 55\%, 28\% e $26 \%$ de queixas, respectivamente.

A prioridade atribuída às necessidades de saúde da população brasileira se presentifica no Pacto pela Saúde. No entanto, não parece favorecer o duplo desafio a ser enfrentado, ou seja, assegurar serviços de qualidade para os idosos e desenvolver, concomitante, recursos humanos de excelência e conhecimento para lidar com o grupo etário que mais cresce no Brasil. $^{5}$

0 modelo hierarquizado do SUS preconiza que as unidades básicas de saúde sejam as portas de entrada do usuário ao sistema. Verificamos em nosso cotidiano que o acesso de pessoas idosas nos serviços do sistema de saúde, em nosso país, ainda se dá majoritariamente pelo pronto atendimento, 
ou seja, quando o idoso já apresenta demandas de fragilidade. Em uma análise mais detalhada da situação sobre a assistência ao idoso, observamos o contraponto entre a assistência individual e curativista e a assistência coletiva, de caráter promocional e preventivo. Nesse sentido, podemos afirmar que a insuficiência de infraestrutura e de planejamento é produto da lacuna ainda existente entre as práticas assistenciais e as políticas públicas de atenção a esse segmento populacional, 0 que abrange desde a organização dos serviços no nível primário de atenção à saúde, a formação de recursos humanos, até a rede de apoio formal e informal. São esses os fatos que se refletem nas condições de assistência à saúde desse grupo e que levaram à realização de experiências e estudos, e conferem direcionamento à nossa trajetória profissional e o envolvimento dos profissionais de saúde com essa clientela.

Não se pode deixar de mencionar que a promoção do cuidado integral ao idoso depende de se considerar os padrões diferenciados de velhice. Portanto, o conceito de atenção integral ao idoso deverá ser efetivado de forma integral, não apenas direcionado exclusivamente para a saúde-doença, mas procurando atendê-lo em suas reais necessidades, sejam elas físicas, morais, sociais, culturais, emocionais e espirituais, possibilitando a garantia de seus direitos à saúde, como cidadão brasileiro.

Por tudo isso, uma forma de responder as necessidades sociais e de saúde no âmbito geral é a efetividade de políticas transversais e integradas, voltadas ao enfrentamento das condições inadequadas de vida do grupo em pauta e a sua integração com outras pessoas em particular, em especial com indivíduos da mesma faixa etária que a sua, proporcionando-lhes atividades e ocupação. ${ }^{6}$ Aqui cabe chamar a atenção para os modelos assistenciais que assumem o grupo idoso como prioridade, considerando suas características biopsicossociais e fazendo com que as atividades sejam estabelecidas de acordo com as necessidades expressadas pelos idosos, sujeitos ativos no controle de sua própria vida e saúde.

Esse entendimento leva em conta a necessidade de fortalecer as práticas de autocuidado e a adoção de estilo de vida saudável pela difusão de saberes nos espaços de convivência de idosos que assegurem a manutenção da autonomia e a capacidade funcional, e sustentem a valorização como pessoa e a busca de um novo sentido para a vida.

Por fim, acreditamos que é preciso avançar as discussões para melhor fundamentar e compreender, numa perspectiva mais abrangente, a problemática da assistência à saúde desse importante segmento populacional, ainda não contemplado em sua integralidade nas políticas públicas de atenção à saúde da mulher

Delineamos comoobjetivos descrever o perfil das mulheres idosas que procuram o serviço especializado e analisar a situação de saúde e da atenção, com enfoque prioritário para a melhoria da qualidade da assistência, tendo como referência o nível de satisfação atendido dessa clientela.
Trata-se de um relato de experiência acerca da participação das mulheres idosas no Programa de Assistência Integral à Pessoa Idosa (PAIPI), do Hospital Escola São Francisco de Assis (HESFA), da Universidade Federal do Rio de Janeiro, sob a coordenação de docentes da Escola de Enfermagem Anna Nery.

\section{POLÍTICAS PÚBLICAS DE ATENÇÃO À SAÚDE DA POPULAÇÃO IDOSA}

A velhice, historicamente enfocada como um fenômeno biológico e restrito à esfera privada, é uma questão central nos debates sobre as políticas públicas; isso porque o aumento em números absolutos e relativos das pessoas idosas é um dos principais desafios políticos para o século XXI.

0 crescimento da população idosa, em números absolutos e relativos, é um fenômeno mundial e está ocorrendo de forma sem precedentes. Em 1950, eram cerca de 204 milhões de idosos no mundo, e, em 1998, quase cinco décadas depois, esse contingente alcançava 579 milhões de pessoas, um crescimento de quase oito milhões de pessoas idosas por ano. As projeções indicam que em 2050, a população idosa será de 1,9 bilhão de pessoas?.

No Brasil, a população com idade igual ou superior a 60 anos soma mais de 14,5 milhões de pessoas, o que representa $8,56 \%$ da população total, sendo que quase dois milhões estão acima dos 75 anos, e destes, cerca de 25 mil estão acima dos 100 anos. Chama a atenção que dessa população, que já viveu 100 anos ou mais, quase $90 \%$ são mulheres. ${ }^{7}$

OSistema Único de Saúde (SUS), por meio de políticas e programas de saúde, busca empreender mudanças no modelo assistencial dominante na assistência ao idoso, como uma das estratégias do SUS e das seis prioridades do Pacto pela Vida, ${ }^{8}$ em uma proposta de reafirmar os princípios ideários da Reforma Sanitária Brasileira, como Universalidade, Equidade, Integralidade e Participação Social. Assumiram o compromisso público os gestores das três esferas do Sistema Único de Saúde na construção e validação do Pacto pela Saúde.

Entretanto, um passo importante nessa discussão inicial foi a Conferência Internacional sobre Cuidados Primários de Saúde de Alma-Ata, realizada em 1978, onde representantes de 134 países foram signatários do documento que se constituiu a meta social para o Ano 2000, denominado "Saúde Para Todos no Ano 2000". Este documento trata dos:

Preceitos ético-humanitários a serem seguidos pela comunidade internacional, buscando uma melhor qualidade de vida do ser humano, através da distribuição de justiça social e da melhoria da qualidade e do acesso universal aos cuidados de saúde?. 
Podemos destacar a relevância desse documento, por seu caráter de denúncia das injustiças sociais e internacionais e pela ênfase à necessidade de revisão do conceito de saúde, em especial à saúde do idoso. Na mesma linha de pensamento, propôs a Conferência que fossem concretizadas novas formas de relacionamento entre os países desenvolvidos e em desenvolvimento para que se pudesse atingir a meta de saúde proposta para o ano 2000 e reduzir as desigualdades de natureza social que afligiam as populações dos países mais pobres.

Outro aspecto fundamental, consagrado naquele importante evento, relaciona-se com o destaque à democratização do processo de planejamento das políticas de saúde. A esse respeito, as conclusões da referida Conferência indicavam:

A participação individual e coletiva na formulação e execução de suas políticas de saúde, sendo responsabilidade dos governos desenvolver políticas, estratégias e planos nacionais de saúde, visando à oferta plena e de boa qualidade dos cuidados à saúde?.

A formulação das políticas voltadas ao idoso foi marcada por eventos significativos no início da década de 70. Em 1978, a Organização das Nações Unidas (ONU), através da Resolução 33/52, convocou a I Assembleia Mundial sobre o Envelhecimento, realizada em 1982 na cidade de Viena, na Áustria. A Assembleia deu origem ao Plano Internacional sobre o Envelhecimento. Não há como deixar de reconhecer que esse documento caracterizou-se, principalmente, por seu conteúdo de se constituir a base das políticas públicas elaboradas para este grupo populacional.

Mais tarde, em 2002, a ênfase na participação social deste grupo populacional nasce do debate em torno do tema "Uma sociedade para todas as idades", quando se realiza a II Assembleia Internacional sobre o Envelhecimento, em Madri, com o objetivo de analisar os resultados da I Assembleia e aprovar as revisões do Plano de Ação.

0 Plano de Ação Internacional de Madri sobre 0 Envelhecimento aponta para as três prioridades em nível mundial: os idosos e o processo de envelhecimento; promoção da saúde e do bem-estar em todas as etapas do ciclo da vida e a criação de contextos favoráveis, que promovam políticas orientadas para a família e a comunidade como base para um envelhecimento seguro. A nosso ver, a questão principal de que trata esse Plano está no reconhecimento da pobreza e da exclusão como empecilho para se alcançar uma velhice digna e respeitosa à dignidade do ser humano.

Dentro dessa perspectiva, a II Assembleia, reforça o conceito de envelhecimento ativo, considerado o processo pelo qual se aperfeiçoam as oportunidades de bem-estar físico, social e mental durante toda a vida, com o objetivo de ampliar a expectativa de vida saudável, a produtividade e a qualidade de vida na velhice. Contudo, quando se aborda o conceito de envelhecimento ativo, é necessário entender que a questão central não se relaciona à produtividade do idoso, mas para a sua representação da velhice, como sinônimo de vitalidade e saúde. Nesse sentido, a motivação e incentivo dessa população que sofre a discriminação social tanto pela idade quanto pela aposentadoria é necessária e essencial para sua qualidade de vida e estímulo para viver de forma saudável em nossa sociedade, sem discriminação ou descaso.

No Brasil, a exemplo de outros países, o crescente aumento da população idosa vem promovendo mudanças das políticas nacionais, e 0 alinhamento com as diretrizes das Assembleias de Viena e de Madri. Mencionam-se como exemplos de dispositivos legais norteadores das ações sociais e de saúde: a Política Nacional do Idoso (PNI), a Política Nacional de Saúde da Pessoa Idosa (PNSPI) e o Estatuto do Idoso.'

A PNI, lei n 8.842 de $04 / 01 / 94$, regulamentada pelo Decreto N01948 de 13/07/96, traz o idoso como protagonista e destinatário das mudanças a serem efetivadas através da implementação de uma política de reinserção social do idoso. Dentre as suas principais diretrizes, destaca-se a criação de estratégias e formas alternativas de participação, ocupação e

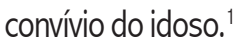

A PNSPI, reatualizada pela Portaria GM/MS n. 2.528/ 2006, tem como meta a atenção integral à saúde da população idosa, principalmente dos idosos frágeis e/ou vulneráveis, articulada à Estratégia Saúde da Família. Nesse mesmo ano, foi publicado o Pacto pela Saúde (Portaria GM/MS 399/2006), e a saúde do idoso é apontada como uma das seis prioridades pactuadas entre as três esferas de governo no SUS. ${ }^{8}$

0 Estatuto do Idoso, sancionado em 2003, foi elaborado com o intuito de garantir aos idosos direitos de proteção à saúde e à vida. ${ }^{2}$

Apesar de esses dispositivos legais representarem um avanço na tentativa de assegurar a proteção ao segmento populacional idoso, é sabido que sua efetivação depende do compromisso ético firmado pelo Estado, pelo idoso e pela sociedade em geral, e do entendimento de que todos estão implicados nesse processo, sendo, portanto, agentes viabilizadores da concretização das políticas públicas de saúde dirigidas às pessoas idosas.

\section{A SAÚDE DA MULHER :DIREITOS E DEVERES COMO UM IMPERATIVO PARA A QUALIDADE DA ATENÇÃO}

Acreditamos ser oportuno e necessário aprofundar a reflexão acerca da saúde da mulher idosa, no contexto do processo de envelhecimento populacional no Brasil, observando em quase todos os países a feminização da velhice, visto que em 2008, havia 94,8 homens para cada 100 mulheres de 60 anos ou mais, principalmente por causa da sobremor talidade masculina. Atualmente, o número de mulheres é superior ao de 
homens tanto no total do país quanto nas áreas urbanas, enquanto nas áreas rurais há mais homens do que mulheres. ${ }^{9}$

Esse fenômeno é explicado pelo fato de que no Brasil as mulheres vivem em média oito anos a mais do que os homens, o que pode ser atribuído a fatores biológicos, em especial pela proteção hormonal de estrógeno, e à diferença de exposição aos fatores de risco de mortalidade; a inserção diferenciada no mercado de trabalho, o uso/abuso de tabaco e álcool, e também a diferença de atitude em relação à saúde/doença, considerando que a mulher busca mais os serviços de saúde, o que mostra maior preocupação com autocuidado. ${ }^{10}$

No entanto, as consequências da feminização da velhice em termos sociais são evidentes, a maioria das mulheres idosas de hoje não teve um trabalho remunerado durante a vida adulta e, consequentemente, é mais pobre e tem menor grau de escolaridade; ${ }^{10}$ nesse contexto, elas estão expostas por períodos mais longos a doenças crônico-degenerativas, à viuvez e à solidão.

Em estudo realizado no Rio de Janeiro, constatou-se que os problemas mais significativos entre as mulheres mais idosas são a solidão, a pobreza e a privação social, sobretudo entre as viúvas mais velhas e as mulheres que vivem sozinhas e dependem de ajuda para sobreviver. ${ }^{11}$

Da mesma forma, o processo de envelhecimento ocasiona riscos crescentes à mulher em termos de saúde, funcionalidade, proteção e integração social. Esses riscos são derivados de fatores biológicos, relacionados ao estilo de vida, histórico de saúde e doença, pobreza, baixa escolaridade e isolamento social. Também é preciso reconhecer que as maneiras de viver/envelhecer dependem da combinação de gênero e classe social.

Por outro lado, mulheres idosas procuram a ressignificação de seus interesses em espaços de convivência. Elas participam mais do que os homens em atividades coletivas fora do espaço doméstico. Mulheres das classes populares utilizam esses espaços para alçar a liberdade. As de classe média buscam as universidades, para atualizar-se e aprender sobre o mundo e sobre si próprias. ${ }^{12}$

Cabe destacar, também, que as mulheres são mais envolvidas social e afetivamente; isso, por um lado, atua a favor da qualidade da saúde desse contingente populacional. Nesse sentido, qualidade da saúde é um conceito complexo que envolve componentes sociais, culturais, científicos, demandas individuais e coletivas, e a produção e consumo de cuidados em saúde. Para dar conta da complexidade da questão da qualidade da saúde e facilitar a compreensão desse conceito, utilizaremos como indicadores a acessibilidade e eficiência das ações destinadas à promoção e prevenção da saúde das mulheres idosas.

No que se refere aos direitos reprodutivos e saúde da mulher - uma das mais importantes questões da Saúde Pública -, ainda são poucos os avanços registrados. Inúmeros são os indicadores sociais que demonstram o descaso com esta área da saúde materna e neonatal: 0 alto índice de mortes maternas, altas taxas de infecções puerperais e hemorragias, abortos realizados clandestinamente, elevado quantitativo de cirurgias cesarianas, ausência de alternativas para o controle da fecundidade, a intensa prática da esterilização de mulheres; altas taxas de morbimortalidade por câncer ginecológico, com o crescente comparecimento das mulheres nas estatísticas da AIDS, entre outros. ${ }^{13}$

Esse quadro caótico da saúde feminina reflete-se na velhice e demonstra a relevância e a necessidade de reforço da assistência à saúde da mulher, considerando o climatério e a menopausa, dentro do contexto da saúde coletiva, de forma a contribuir para uma efetiva mudança no perfil da atenção de serviços de atenção à população feminina e à sua saúde nas diferentes etapas do ciclo de vida.

\section{AS EXPERIÊNCIAS DA MULHERES IDOSAS NO PAIPI:A QUALIDADE DE VIDA E SAÚDE}

0 Programa de Assistência Integral à Pessoa Idosa (PAIPI) foi instituído em julho de 1988 no Hospital Escola São Francisco de Assis (HESFA) da Universidade Federal do Rio de Janeiro. Na realidade, é uma proposta pedagógica e assistencial de elevada significação social e acadêmica resultado do empenho de docentes da Escola de Enfermagem Anna Nery (EEAN/UFRJ) e dos profissionais do HESFA/UFRJ. Sua formulação foi visionária pautada na abordagem cientíica das demandas da população idosa brasileira, manteve o compromisso com a proposta institucional, assegurou ao conjunto institucional envolvido e à UFRJ um caráter de pioneirismo abrangendo a assistência, ensino, pesquisa e extensão. ${ }^{14}$

O PAIPI abrange um Centro de Convivência e atividades ambulatoriais voltados para a saúde do idoso. 0 Centro de Convivência está estruturado segundo um modelo assistencial que tem na grupalidade a medida propiciadora de práticas socioeducativas e de promoção da saúde visando o autocuidado, a reinserção social e a autodeterminação das pessoas idosas. Além disso, é o cenário do desenvolvimento de programas de ensino de graduação e treinamento profissional, que oferece os fundamentos conceituais, teóricos e práticos em diferentes áreas de domínio da Gerontologia.

Vale mencionar que o Centro de Convivência contempla a produção de conhecimentos através do envolvimento de docentes, discentes, profissionais, voluntários e usuários na pesquisa. A abordagem é gerontológica porque engloba os aspectos biopsicossociais e educacionais do idoso-familia, pela articulação nos campos da Enfermagem Gerontológica, Geriatria, Fisioterapia, Psicologia, Fonoaudiologia, Terapia Ocupacional, Assistência Social e Pedagogia, dentre outros, de modo a formar uma rede de cuidados gerontológicos, onde possibilite a compatibilização entre os objetivos da formação de enfermeiros e um trabalho multidisciplinar de apoio e 
assistência a essa clientela. É nesse campo de experiências e práticas que buscamos interagir com os idosos de forma a proporcionar a qualidade da atenção por meio de estratégias que permitam minimizar os efeitos sociais individuais e ou familiar, trazendo mudanças substantivas para a qualidade de vida e saúde. Procuramos identificar no perfil dos idosos um diagnóstico das necessidades e expectativas a fim de viabilizar ações que possibilitem mudanças na convivência com o grupo e a inserção deste com as atividades propostas.

Nesse contexto, são oferecidas atividades das mais diversificadas no sentido de atender a demanda específica e proporcionar a satisfação da clientela atendida no PAIPI. Estas atividades são desenvolvidas com o objetivo primordial de captar a comunicação não verbal e as manifestações que pudessem expressar os sentimentos, interesses, participação, criatividade e, especialmente, trabalhar a expressão corporal em atividades que requeiram maior socialização e estimulação de sua capacidade funcional e autonomia do idoso. Vale salientar que as atividades corporais podem ser mais importantes que a própria situação da morbidade, pois se relacionam diretamente com a qualidade de vida proporcionando saúde e bem-estar.

Desta forma, vários grupos de trabalho foram criados decorrentes da necessidade das demandas apresentadas no intuito de se obter $\mathrm{o}$ alcance das propostas elaboradas nesse Programa. São exemplos desse trabalho coletivo e multiprofissional os grupos abaixo especificados:

- Grupo de atividade autoexpressiva: criado principalmente para desenvolver o potencial criativo, elaboração dos conteúdos internos por meio da expressão corporal e dramatização, socialização e estimulação das funções perceptivas e cognitivas.

- Oficina de alfabetização: foi elaborada e desenvolvida à luz da Pedagogia Problematizadora de Paulo Freire. Objetiva possibilitar o acesso à educação continuada às pessoas idosas, criar oportunidades de aquisição de novos conhecimentos, proporcionar a atualização de valores, atitudes e informações, respeitando-se a sabedoria dos mesmos e estimular a formulação de novos projetos de vida. A oficina, ao promover a ampliação de conhecimentos mediante um saber mais sistematizado, é avaliada como geradora de melhoria da autoestima por valorizar o autoaperfeiçoamento da pessoa idosa.

- Ciclo de debates: está voltado para as questões que são de interesse geral visando à educação em saúde, particularmente sobre o processo de envelhecimento. Os temas abordados são solicitados pelos próprios idosos aproveitando-se para, na oportunidade esclarecer suas dúvidas, fazer paralelas com assuntos pertinentes, inclusive comentários com assuntos trazidos pela mídia. Dessa forma, desperta-se o interesse à promoção da saúde abordando mitos e preconceitos. Insere-se a ideia de saúde sob o olhar da pessoa, privilegiando-se a capacidade funcional, estimulando a autonomia e a independência obtida através da sinergia do tratamento multidisciplinar.
- Grupo informativo e reflexivo: objetiva promover a adaptação às mudanças inerentes ao processo de envelhecimento; aprimorar o senso crítico e a reflexão, trabalhando a cidadania por intermédio da troca de experiências; integrar o idoso ao meio familiar e a sociedade ampliando a rede de solidariedade desse grupo societário, ressaltar as potencialidades dos idosos no sentido realista de sua capacidade funcional e limitações.

- Oficina de memória e criatividade: desenvolvimento de atividades criativas para reativar e manter a memória; usar técnicas que estimulem o desenvolvimento da memória, visando melhoria da qualidade de vida; criação de condições ambientais e emocionais para o desenvolvimento de habilidades manuais e intelectuais; incentivar a construção de trabalhos, produtos, obras ou qualquer outra atividade para que se sintam integrados à família e à comunidade a que pertence.

- Grupo vivenciando a dança: objetiva o fortalecimento e estimulação da criatividade, desenvolvimento da autoimagem, conscientização corporal, coordenação motora global e equilíbrio, ritmo, noção temporal, consciência pelo movimento, técnicas de respiração, relaxamento, socialização e percepção (auditiva, tátil, perceptiva, sensorial), além da noção de lateralidade.

- Grupo de dança sênior: atividade com coreografias de movimentos leves e ritmados do folclore europeu e nacional, que objetiva integrar o grupo e estimular a percepção auditiva, a consciência corporal e a lateralidade.

- Oficinas de artesanato: objetiva maior socialização, valorização do saber, reconhecimento dos talentos e da capacidade de aprendizagem permanente dos idosos.

- Grupo sociocultural: constitui-se de atividades diversas, entre elas, o grupo de discussão na unidade que articula questões sócio-histórico-culturais ao cotidiano dos idosos; visitas em museus, centros e espaços culturais. Objetiva o reconhecimento da educação e cultura como espaços de exercício da cidadania.

Caracterizando o perfil das participantes e a inserção nas atividades do centro de convivência do PAIPI no Hospital Escola São Francisco de Assis (HESFA), utilizamos dados secundários que foram extraídos das fichas de cadastro do Programa, o que permitiu verificar que, atualmente, o Centro de Convivência comporta 185 inscritos. Desse quantitativo, 180 são mulheres, portanto a grande maioria. A média de idade foi de 70 anos, variando entre 60 anos, a idade mínima, e 83 anos, a máxima. Observou-se a predominância de mulheres da raça negra. A escolaridade variou entre analfabetismo funcional e o ensino fundamental. 0 número médio de anos de estudo foi de 4 anos, ou seja, a maioria tinha o ensino fundamental incompleto. A viuvez foi o estado conjugal prevalecente entre as mulheres. A maioria possui filhos (88,9\%). A composição familiar correspondeu à 
grande maioria (65\%), vivendo em domicílios multigeracionais, enquanto $13 \%$ viviam sós. Todas as mulheres tinham renda própria, e se observou uma concentração em faixas de renda pertencentes a estratos economicamente desfavorecidos. Constatamos que $61,5 \%$ eram arrimos de família, outras mantinham apenas a si mesmas $(26,7 \%)$. A maior parte $(69,5 \%)$ apresentava pelo menos um agravo crônico- com destaque para a hipertensão arterial referida por $66,3 \%$ das idosas, seguida de osteoartroses. Além disso, apontavam como justificativas para a inserção no PAIPI os sentimentos de solidão e a depressão, ${ }^{16}$ além da necessidade de ocupação do tempo livre. As idosas apresentavam bons indicadores de autonomia e independência funcional, uma vez que se diziam capazes de realizar sozinhas as atividades da vida diária (AVD). A religião predominante foi a católica $(84,0 \%)$. Constatamos que o tempo médio de frequência ao PAIPI foi de 10 anos. A maioria frequentava as atividades do Centro de Convivência três vezes na semana.

Os serviços de saúde que têm acesso e regularmente utilizam no PAIPI/HESFA são as consultas de enfermagem gerontológica, consultas geriátrica, nutrição e farmacêutica, atendimento no serviço social e na psicologia. Destacamos, dentre outros, o contato com estudantes de graduação e pós-graduação dos cursos da Universidade Federal do Rio de Janeiro. Nesse sentido, o PAIPI tem contribuído no processo de formação dos estudantes de enfermagem na medida em que é cenário do trabalho de campo do Programa Curricular Interdepartamental IV do Departamento de Enfermagem de Saúde Pública da Escola de Enfermagem Anna Nery/UFRJ. Esses alunos desenvolvem atividades com a presença de docentes e equipe multidisciplinar, de forma integrada, na consulta de enfermagem gerontológica, em palestras, orientações, procedimentos e práticas educativas sobre cuidados com a saúde, visando à melhoria da condição de saúde e da qualidade de vida dos idosos.

As mulheres participantes dos grupos e oficinas quase sempre buscam novas sociabilidades e que correspondam às suas motivações e necessidades. Nos grupos há aquelas que mantêm uma assiduidade regular, e outras têm uma presença mais esporádica, muito embora a incidência de evasão seja muito baixa. Isso demonstra a valorização do PAIPI em relação à atenção à saúde do idoso e à clientela que procura o referido Programa.

Cabe mencionar outros aspectos resultantes de nossas buscas: é no espaço grupal que as mulheres expressam as vivências próprias do seu viver/envelhecer trazendo à luz a problemática de ser mulher e idosa. De certa forma, a qualidade da assistência à saúde desse grupo é intermediada pela troca de saberes no espaço grupal dialógico, favorecendo as alianças que dão forma a difusão das práticas de autocuidado e fortalecimento dos vínculos sociais. ${ }^{15}$

\section{CONSIDERAÇÕES FINAIS}

Acreditamos ser oportuno e necessário aprofundar a reflexão acerca da saúde do idoso, em especial nesse grupo de mulheres idosas, no contexto do processo de envelhecimento populacional no Brasil, uma vez que se tem observado em quase todos os países a desigualdade de gênero na expectativa de vida. Os dados apontam que, em 2008, havia 94,8 de homens para cada 100 mulheres de 60 anos ou mais, principalmente por causa da sobremortalidade masculina. Esse quadro mostra que o número de mulheres é superior ao de homens tanto no total do país quanto nas áreas urbanas, enquanto nas áreas rurais há mais homens do que mulheres.

Atualmente, parece haver consenso de que o bemestar da pessoa idosa não deve ser creditado apenas às relações de cuidado por parte de familiares ou profissionais. Ele se baseia, muito mais, em políticas públicas inclusivas que assegurem os direitos do idoso, criando condições para a promoção da saúde, autonomia, integração e participação social. Tal alegação está fundamentada na necessidade de se definir novos espaços sociais para as pessoas idosas. De modo geral, tanto o cenário internacional quanto o nacional permitem, hoje, reunir elementos suficientes para compreender as implicações desse fenômeno nas sociedades contemporâneas e abrir espaços para novas discussões.

Respeitar as mulheres idosas é respeitá-las em sua integralidade, proporcionar-Ihes atividades culturais, de lazer e educativas; para poderem se deslocar de um lugar a outro com segurança e conforto, para que exerçam seu direito à liberdade; desenvolver ambiente de convívio pacífico, sendo assegurados o bem-estar e a efetivação do seu direito à vida. 0 atendimento à idosa deve ser uma preocupação constante dos profissionais de saúde, desenvolvido integralmente, considerando suas expectativas e necessidades físicas, emocionais, espirituais e sociais, integrando-a com outras pessoas, em especial com indivíduos da mesma faixa etária, de forma a possibilitar a melhoria da qualidade e condições de vida e de saúde individual e convívio no ambiente familiar.

Desse modo, podemos afirmar que o PAIPI é a evidência objetiva de um modelo de cuidado integral à saúde da pessoa idosa, considerando-se que desenvolve práticas congruentes com as necessidades e especificidades de cada mulher na velhice. A qualidade das práticas individuais e coletivas tem contribuído para o protagonismo dessas mulheres no meio familiar e comunitário. Isso equivale a dizer que representa mais que um espaço de lazer e entretenimento, na medida em que contribui para melhor integração social e participativa, amplia a rede social, permitindo uma comunicação na interrelação entre as mulheres idosas e possibilita uma vida mais ativa e saudável. 


\section{REFERÊNCIAS}

1.Ministério da Previdência Social (BR). Plano integrado de ação governamental para o desenvolvimento da política nacional do idoso. Brasília (DF); 1997.

2.Ministério da Saúde (BR). Lei n 10741 , de $1^{\circ}$ de outubro de 2003. Estatuto do Idoso. Disponível em http://www.planalto.gov.br/civil/LEIS/ 2003/L10.741.htm .

3.Ministério da Saúde (BR). Centro de Educação e Assessoramento PopularCEAP. Pacto pela saúde: possibilidade ou realidade? $2^{\mathrm{a}}$ ed. Passo Fundo (RS): IFIBE; 2009. p.7

4.Ministério da Saúde (BR). Secretaria de Gestão Estratégica e Participativa. Departamento de Monitoramento e Avaliação da Gestão do SUS. Painel de indicadores do SUS, 2. Saúde da Mulher 2007; 1:18.

5.Figueiredo MLF, et al. Educação em saúde e mulheres idosas: promoção de conquistas políticas, sociais e em saúde. Esc Anna Nery 2006 dez; 10 (3): 456-61

6.Martins MS, Massarollo MCKB. Mudanças na assistência ao idoso após promulgação do Estatuto do Idoso segundo profissionais de hospital geriátrico. Rev Esc Enferm USP 2008; 42(1): 26-33.

7.Instituto Brasileiro de Geografia e Estatística- IBGE. Perfil dos idosos responsáveis pelos domicílios no Brasil. Rio de Janeiro(RJ); 2002 [citado 2010 abr 16]. Disponível em: http://www.ibge.gov.br..

8.Ministério da Saúde (BR). Diretrizes operacionais dos pactos pela vida, em defesa do SUS e de gestão. Brasília (DF); 2006.

9.Ministério da Saúde (BR). Secretaria de Gestão Estratégica e Participativa. Departamento de Monitoramento e Avaliação da Gestão do SUS. Brasília (DF), Painel de indicadores do SUS 2006 out; 19 (1): 7-13.

10.Instituto Brasileiro de Geografia e Estatística- IBGE. Síntese de Indicadores Sociais: uma análise das condições de vida da população brasileira. Rio de Janeiro(RJ); 2008.

11.Debert GGA. A reinvenção da velhice: socialização e processos de reprivatização do envelhecimento. São Paulo(SP): USP/FAPESP; 2000.

12.Veras RP, Caldas CP. Promovendo a saúde e a cidadania do idoso: 0 movimento das universidades da terceira idade. Cienc Saude Colet. 2004. abr/jun; 9 (2):

13.Ministério da Saúde (BR). Agência Nacional de Saúde Suplementar. 0 modelo de atenção obstétrica no setor de saúde suplementar no Brasil: cenários e perspectivas. Rio de Janeiro (RJ): ANS; 2008. p. 158

14.Domingos AM, Meneses IG. Sobreo apoio social em um centro de convivência: a percepção dos idosos. Rede Latinoamericana de Gerontologia. [on-line] nov. 2005. [citado 2010 abr 16]. Disponível em: www.gerontologia.com

15.Ministério da Saúde (BR). Secretaria de Gestão Estratégica e Participativa. Departamento de Monitoramento e Avaliação da Gestão do SUS Painel de indicadores do SUS. Saúde da Família 2008 ago; 5(2): 9- 